\title{
Characteristics of Nanoclay and Calcined Nanoclay-Cement Nanocomposites
}

\author{
Hakamy A ${ }^{1,2}$, Shaikh, F.U.A. ${ }^{3}$, Low I.M*1
}

${ }^{1}$ Department of Imaging \& Applied Physics, Curtin University, GPO Box U1987, Perth, WA 6845, Australia

${ }^{2}$ Department of Physics, Umm Al-Qura University, P.O.Box 715, Makkah, Saudi Arabia

${ }^{3}$ Department of Civil Engineering, Curtin University, GPO Box U1987, Perth, WA 6845, Australia

*Corresponding author. Email: j.low@curtin.edu.au

\section{ABSTRACT}

The influence of nanoclay (NC) and calcined nanoclay (CNC) on the mechanical and thermal properties of cement nano-composites presented. Calcined nanoclay is prepared by heating nanoclay (Cloisite 30B) at $900^{\circ} \mathrm{C}$ for $2 \mathrm{~h}$. Characterisation of microstructure is investigated using Quantitative X-ray Diffraction Analysis (QXDA) and High Resolution Transmission Electron Microscopy (HRTEM). Estimation of $\mathrm{Ca}(\mathrm{OH})_{2}$ content in the cement nanocomposite is studied by the combination of QXDA and thermogravimetry analysis (TGA) techniques. Results showed that the mechanical and thermal properties of the cement nanocomposites are improved as a result of NC and CNC addition. An optimum replacement of ordinary Portland cement with 1 wt $\% \mathrm{CNC}$ is observed through reduced porosity and water absorption as well as increased density, compressive strength, flexural strength, fracture toughness, impact strength, hardness and thermal stability of cement nanocomposites. The microstructural analyses from QXRA and SEM indicate that the CNC acted not only as a filler to improve the microstructure, but also as 
the activator to support the pozzolanic reaction. Cost-benefit analysis indicates that nanoparticles are expensive but from economic point of view nanoclay is used in very small amount (i.e. $1 \mathrm{wt}$. $\%$ ) in cementitious materials. As a result nanoclay does not add any significant cost but improves the mechanical properties significantly.

Keywords: A. Nano-structures; B. Mechanical properties; B. Thermal properties; D. Mechanical testing; E. Thermal analysis.

\section{Introduction}

Nowadays, nanotechnology is one of the most active research areas in the civil engineering and construction materials [1-3]. Nanoparticles are used in polymer, ceramic and construction materials in order to produce cement nanocomposites that exhibit superior physical and mechanical properties $[4,5]$. In the construction industry, several types of nanomaterials have been incorporated into concretes or cement based materials such as nano- $\mathrm{SiO}_{2}$, nano- $\mathrm{Al}_{2} \mathrm{O}_{3}$, nano- $\mathrm{Fe}_{2} \mathrm{O}_{3}$, nano- $\mathrm{ZnO}_{2}$, nano- $\mathrm{MgO}$, nano- $\mathrm{CaCO}_{3}$, nano- $\mathrm{TiO}_{2}$, carbon nanotubes, nanometakaolin and nano- $\mathrm{ZrO}_{2}$ in order to improve the durability and mechanical properties of concrete and Portland cement matrix [6-10]. Supit and Shaikh [11] reported that the addition of $1 \%$ nano- $\mathrm{CaCO}_{3}$ increased the compressive strength of mortar and concrete significantly. Nanosilica (NS) has recently been introduced as an advanced pozzolan to improve the microstructure and stability of cement based system [12]. It has been observed that the NS consumed free lime (calcium hydroxide) during cement hydration and formed calcium silicate hydrate (CSH) gel due to its high fineness and reactivity [13]. In addition, the NS is particularly beneficial in acting as a nucleus to make the cement hydrate dense and improves the interfacial transition zone despite of small amount of replacement. From some conducted experiments, Zhang and Islam [14] and Jo 
et al. [15] reported better performance of concrete containing NS than that containing silica fume. Nano silica also improved the microstructure and mechanical properties of high calcium fly ash based geopolymer cured at ambient temperature [16].

Nanoclay (NC) is a new generation of processed clay for a wide range of high-performance cement nanocomposite $[17,18]$. As a kind of nano-pozzolanic material, nanoclay not only reduces the pore size and porosity of the cement matrix, but also improves the strength of cement matrix [19]. Furthermore, nanoclay particles enhance hardened properties of cement paste and mortar. Farzadnia et al. [20] reported that incorporation of 3\% halloysite nanoclay into cement

mortars increased the $28^{\text {th }}$ day compressive strength up to $24 \%$ compared to the control samples. However, little research is reported on the use of calcined nanoclay (CNC) as reinforcement in cement nanocomposite. In this paper, the effect of different amounts of nanoclay and calcined nanoclay on the mechanical and thermal properties of cement nanocomposite is studied. Due to calcination the amorphous contents of nanoclay is increased, which later reacted with $\mathrm{Ca}(\mathrm{OH})_{2}$ of the cement hydration products and formed additional calcium-silica-hydrate (CSH) gel. The benefit of the use of $\mathrm{CNC}$ is the improvement of microstructure of the cement nanocomposite. The microstructures of cement nanocomposite were investigated using Quantitative X-ray Diffraction Analysis (QXDA) and High Resolution Transmission Electron Microscopy (HRTEM).

\section{Experimental procedure}

\subsection{Materials}

The nanoclay platelets (Cloisite 30B) used in this investigation is a natural montmorillonite modified with a quaternary ammonium salt, which was supplied by Southern Clay Products, 
USA. The specification and physical properties of Cloisite 30B are shown in Table 1. Ordinary Portland cement (ASTM Type I) was used in all mixes.

\subsection{Thermal treatment of nanoclay}

Calcined nanoclay (CNC) was prepared by heating the nanoclay at 800,850 and $900^{\circ} \mathrm{C}$ for $2 \mathrm{~h}$ in an electric furnace with a heating rate of $10^{\circ} \mathrm{C} / \mathrm{min}$. The calcined nanoclay was then characterized by XRD, EDS and TEM in order to determine the amorphous phase of calcined nanoclay.

\subsection{Sample preparation}

\subsubsection{Cement nanocomposite}

Ordinary Portland cement (OPC) is partially substituted by nanoclay (NC) or calcined nanoclay (CNC) of 1,2 and $3 \%$ by weight of OPC. The OPC and NC or CNC were first dry mixed for 5 minutes in a Hobart mixer at a low speed and then mixed for another 10 minutes at high speed until homogeneity was achieved. The binder is either nanoclay-cement dry powder or calcined nanoclay-cement dry powder. The cement nanocomposite paste was prepared through adding water with a water / binder ratio of 0.485 . The cement nanocomposite containing 1, 2 and $3 \mathrm{wt} \%$ $\mathrm{NC}$ is termed as NCC1, NCC2 and NCC3, respectively. And also the cement nanocomposite containing 1, 2 and $3 \mathrm{wt} \% \mathrm{CNC}$ is termed as $\mathrm{CNCC} 1, \mathrm{CNCC} 2$ and $\mathrm{CNCC} 3$, respectively. The cement paste (C) was considered as a control. The mix proportions are shown in Table 2 .

\subsubsection{Curing and specimens}

Regarding each series, five cubes of size $50 \times 50 \times 50 \mathrm{~mm}$ and five prismatic plate specimens of $300 \times 70 \times 10 \mathrm{~mm}$ in dimension were cast. All specimens were demolded after $24 \mathrm{~h}$ of casting and 
kept under water for approximately 56 days. Five rectangular specimens of each series with dimensions $70 \times 20 \times 10 \mathrm{~mm}$ were cut from the fully cured prismatic plate for each mechanical and physical test. For compressive strength test, five cubes of size $50 \times 50 \times 50 \mathrm{~mm}$ were cast.

\subsection{Material Characterisation}

\subsubsection{High Resolution Transmission Electron Microscopy (HRTEM)}

High resolution transmission electron microscopy imaging was done using 3000F (JEOL company) operating at $300 \mathrm{kV}$ equipped with a $4 \times 4 \mathrm{k}$ CCD camera (Gatan). Nanoclay and calcined nanoclay powders were dispersed in ethanol inside small glass containers by using ultrasonic device for 15 minutes. After that few drops of suspension were mounted onto copper grid and then kept to dry for 24 hour at room temperature prior to examination.

\subsubsection{The Quantitative X-ray Diffraction Analysis (QXDA)}

The samples were measured on a D8 Advance Diffractometer (Bruker-AXS) using $\mathrm{Cu} \mathrm{Ka}(\lambda=$ $1.5406 \AA$ ) radiation. The diffractometer were scanned from $7^{\circ}$ to $70^{\circ}(2 \theta)$ using a scanning rate of $0.5 \%$ min. The Quantitative X-ray Diffraction Analysis (QXDA) with Rietveld refinement was done with Bruker DIFFRAC ${ }^{\text {plus }}$ TOPAS software associated with the International Centre for Diffraction Data PDF-4 2013 database. Corundum $\left[\mathrm{Al}_{2} \mathrm{O}_{3}\right]$ was chosen to serve as an internal standard [2, 21-23]. The samples for QXDA were prepared by mixing a dry weight of $3.0 \mathrm{~g}$ of cement paste or cement nanocomposite paste with $0.33 \mathrm{~g}$ of Corundum $\left[\mathrm{Al}_{2} \mathrm{O}_{3}\right]$ as the internal standard $[4,24]$.

\subsubsection{Scanning electron microscopy (SEM)}


Scanning electron microscopy imaging was obtained using a NEON 40ESB, ZEISS, equipped with energy dispersive spectroscopy (EDS). The SEM investigation of samples was carried out in detail on their microstructures and the fractured surfaces. Samples were coated with a thin layer of platinum before observation by SEM to avoid charging.

\subsubsection{Thermogravimetric analysis (TGA)}

The thermal stability of samples was studied by thermogravimetry analysis (TGA). A Mettler Toledo TGA 1 star system analyser was used for all measurements. Samples with $30 \mathrm{mg}$ were placed in an alumina crucible and tests were carried out in Argon atmosphere with a heating rate of $10^{\circ} \mathrm{C} / \mathrm{min}$ from 25 to $1000{ }^{\circ} \mathrm{C}$.

\subsection{Physical properties}

Measurements of bulk density and porosity were conducted to determine the quality of cement nanocomposite. The calculation for density was carried out by using the following equation:

$$
\rho=\frac{m_{d}}{V}
$$

Where, $\rho=$ density in $\left(\mathrm{g} / \mathrm{cm}^{3}\right), m_{d}=$ mass of the dried sample $(\mathrm{g})$ and $V=$ volume of the test specimen $\left(\mathrm{cm}^{3}\right)$.

According to ASTM C-20 Standard [25], the apparent porosity $P_{S}$ was calculated using the following equation:

$$
P_{S}=\frac{m_{s}-m_{d}}{m_{s}-m_{i}} \times 100
$$


Where $m_{i}=$ mass of the sample saturated with and suspended in water, $m_{s}=$ mass of the sample saturated in air.

For the water absorption test, the produced specimens were dried at a temperature of $80{ }^{\circ} \mathrm{C}$ until their mass became constant and then the mass was weighed $\left(\mathrm{W}_{0}\right)$. The specimens were then immersed in clean water at a temperature of $20{ }^{\circ} \mathrm{C}$ for $48 \mathrm{~h}$. After the desired immersion period, the specimens were taken out and wiped quickly with wet cloth, and then the mass was weighed $\left(\mathrm{W}_{1}\right)$ immediately. The water absorption $\left(\mathrm{W}_{\mathrm{A}}\right)$ was calculated by using the formula:

$$
\mathrm{W}_{\mathrm{A}}=\frac{W_{1}-W_{0}}{W_{0}} \times 100
$$

\subsection{Mechanical properties}

\subsubsection{Compressive strength}

Compressive strength of specimens was tested according to ASTM: C109 using a loading rate of $0.33 \mathrm{MPa} / \mathrm{s}$. The cube samples of size $50 \times 50 \times 50 \mathrm{~mm}$ are cast. Five cubic specimens of each composition were used to measure the compressive strength.

\subsubsection{Flexural strength and fracture toughness}

Three-point bend tests were conducted using a LLOYD Material Testing Machine to evaluate the flexural strength and fracture toughness of the specimens. The support span used was $40 \mathrm{~mm}$ with a displacement rate of $0.5 \mathrm{~mm} / \mathrm{min}$. The flexural strength $\sigma_{F}$ was evaluated using the following equation: 


$$
\sigma_{F}=\frac{3 P_{m} S}{2 B W^{2}}
$$

Where $P_{m}$ is the maximum load, $S$ is the span of the sample, $W$ is the specimen depth and $B$ is the specimen width.

In order to determine the fracture toughness, a sharp razor blade was used to initiate a sharp crack in the samples. The ratio of crack length to depth $\left(\frac{a}{W}\right)$ was about $1 / 3$. The fracture toughness was calculated using the following equation [4]:

$$
K_{I C}=\frac{P_{m} S}{B W^{3 / 2}} f\left(\frac{a}{W}\right)
$$

Where $a$ is the crack length $(\mathrm{mm})$ and $f\left(\frac{a}{W}\right)$ is the polynomial geometrical correction factor given by:

$$
f\left(\frac{a}{W}\right)=\frac{3(a / W)^{1 / 2}\left[1.99-(a / W)(1-a / W) \times\left(2.15-3.93 a / W+2.7 a^{2} / W^{2}\right)\right]}{2(1+2 a / W)(1-a / W)^{3 / 2}}
$$

Five specimens, measuring $70 \times 20 \times 10 \mathrm{~mm}$, of each composition were used to measure the flexural strength and the fracture toughness.

\subsubsection{Impact strength}

The impact strength of the specimen was determined using a Zwick Charpy impact tester with 15 Joule pendulum hammer and $40 \mathrm{~mm}$ support span. Un-notched samples were used to compute the impact strength using the following formula: 


$$
\sigma_{I}=\frac{E}{A}
$$

Where $E$ is the impact energy to break a sample with a ligament of area $A$. Five specimens, measuring $70 \times 20 \times 10 \mathrm{~mm}$, of each composition were used to measure the impact strength.

\subsubsection{Rockwell Hardness}

The hardness of the specimen was determined by the Rockwell hardness test, according to the specifications of ASTM E-18. Hardness of specimen was measured on an Avery Rockwell hardness tester using 1/8" H scale steel ball indenter having a major loading capacity of $60 \mathrm{Kg}$. Before measurement, the surfaces of test samples were ground using a Struers Pedimat polisher with $10 \mu \mathrm{m}$ diamond polishing wheel. An average of five measurements from each specimen was used to measure the Rockwell hardness.

\section{Results and discussion}

\subsection{Material Characterisation}

\subsubsection{Effect of thermal treatment on nanoclay microstructure}

\subsubsection{XRD analysis of calcined nanoclay}

Fig. 1 shows the XRD patterns of nanoclay and those calcined at 800,850 and $900{ }^{\circ} \mathrm{C}$ for $2 \mathrm{~h}$, respectively. XRD patterns of nanoclay show wide diffraction peaks which refer to Montmorillonite-18A $\left[\mathrm{Na}_{0.3}(\mathrm{Al}, \mathrm{Mg})_{2} \mathrm{Si}_{4} \mathrm{O}_{10} \mathrm{OH}_{2} \cdot 6 \mathrm{H}_{2} \mathrm{O}\right]$ (PDF000120219) and also exhibit crystalline phase at $2 \theta$ of $4.82^{\circ}$ which indicate the presence of the ammonium salt. Patterns of calcined nanoclay at 800,850 and $900{ }^{\circ} \mathrm{C}$ show that the ammonium salt peak completely disappeared at these temperatures. Also other nanoclay peaks gradually disappeared and 
transformed to amorphous state (calcined nanoclay) at $900{ }^{\circ} \mathrm{C}$ (see curve 'd' in Fig. 1). Results of XRD clearly show the transformation of crystalline phases of nanoclay to amorphous phases due to calcination [26].

\subsubsection{Energy dispersive spectroscopy (EDS) analysis of calcined nanoclay}

Figures $2 \mathrm{a}$ and $2 \mathrm{~b}$ show typical EDS spectra of nanoclay and calcined nanoclay (at $900{ }^{\circ} \mathrm{C}$ ). In

Fig. 2a, ammonium salt in the nanoclay is identified by carbon and nitrogen elements (Fig. 3). The content of nitrogen element is very small, thus EDS cannot detect it but the carbon element is clearly detected at $2.5 \mathrm{KeV}$. However, in Fig. 2b, the carbon element disappeared because of combustion which yielded carbon dioxide during calcination. This result also confirms the decomposition of ammonium salt in calcined nanoclay which agrees with XRD results.

\subsubsection{High Resolution Transmission Electron Microscopy (HRTEM) of calcined nanoclay}

HRTEM images of nanoclay (Cloisite 30B) at low and high magnification are shown in Figs. 4ab. In the high magnification image (Fig. 4b), it can be seen clearly that the distances between the nanoclay platelets (i.e. layers) were about $1.85 \mathrm{~nm}$ and thus this is evidence that the d-spacing of (001) planes in nanoclay layers was $1.85 \mathrm{~nm}$ as shown in Table 1. The HRTEM images for calcined nanoclay (at $900{ }^{\circ} \mathrm{C}$ ) at low and high magnification respectively are shown in Figs. 4cd. In high magnification image (Fig. 4d), it can be seen that many platelets in calcined nanoclay were destroyed and some of them broke to small nanoparticles with approximate spherical shapes ranging 3-8 nm. This result also confirms the amorphous phase of calcined nanoclay which agrees with the XDR results above.

\subsubsection{Quantitative X-ray Diffraction Analysis (QXDA) of cement nanocomposite}


The XRD patterns of cement paste, cement nanocomposite containing 1,2 and $3 \mathrm{wt} \% \mathrm{CNC}$ and cement nanocomposite containing $1 \mathrm{wt} \% \mathrm{NC}$ are shown in Fig. 5 a-e, that included Corundum $\left[\mathrm{Al}_{2} \mathrm{O}_{3}\right]$ (PDF 000461212) phase as the internal standard. Table 3 shows the results of quantitative analysis with Rietveld refinement of cement paste and cement nanocomposite containing $\mathrm{NC}$ and $\mathrm{CNC}$. Three important phases are noticed in this study: portlandite $\left[\mathrm{Ca}(\mathrm{OH})_{2}\right]$ (PDF 00-044-1481), tricalcium silicate $\left[\mathrm{C}_{3} \mathrm{~S}\right](00-049-0442)$ and dicalcium silicate $\left[\mathrm{C}_{2} \mathrm{~S}\right](\mathrm{PDF}$ 00-033-0302). Moreover, four less important phases are also noticed: Ettringite $\left[\mathrm{Ca}_{6} \mathrm{Al}_{2}\left(\mathrm{SO}_{4}\right)_{3}(\mathrm{OH})_{12} \cdot 26 \mathrm{H}_{2} \mathrm{O}\right](\mathrm{PDF} 000411451)$, Gypsum $\left[\mathrm{Ca}\left(\mathrm{SO}_{4}\right)\left(\mathrm{H}_{2} \mathrm{O}\right)_{2}\right](\mathrm{PDF} 040154421)$, Quartz $\left[\mathrm{SiO}_{2}\right](\mathrm{PDF} 000461045)$ and Calcite $\left[\mathrm{CaCO}_{3}\right](\mathrm{PDF} 000050586)[2,21,23,27]$. As can be seen in Table 3 and Fig. 5 b, the addition of $1 \mathrm{wt} \% \mathrm{CNC}$ reduced the amount of $\mathrm{Ca}(\mathrm{OH})_{2}$ from $16.8 \mathrm{wt} \%$ to $12.1 \mathrm{wt} \%$, about $28 \%$ reduction compared to cement paste. Also the intensities of major peaks of $\mathrm{Ca}(\mathrm{OH})_{2}$ were significantly reduced compared to cement paste (Figs. $5 \mathrm{~b}$ and a). Furthermore, the amorphous content was increased from 70.1 to $74.8 \mathrm{wt} \%$, about $6.7 \%$ increase. This indicates that an obvious consumption of $\mathrm{Ca}(\mathrm{OH})_{2}$ crystals mainly due to the effect of pozzolanic reaction in the presence of amorphous $\mathrm{CNC}$ and good dispersion of amorphous calcined nanoclay in the matrix, which leads to more calcium silicate hydrate gel (C-S-H) being produced. This explanation is also confirmed by an increase in the amount of unreacted $\mathrm{C}_{3} \mathrm{~S}(2.0$ wt $\%)$ and $\mathrm{C}_{2} \mathrm{~S}(6.6$ wt \%), relative to the cement paste. Wei et al. [28] reported that pozzolanic reaction decelerates the hydration reaction of $\mathrm{C}_{3} \mathrm{~S}$ and $\mathrm{C}_{2} \mathrm{~S}$ during the curing time of $28-90$ days. In this study, these unreacted phases could react with water later to produce more C-S-H gel after 56 days. Recently, Shaikh et al. [29] reported that the cement nanocomposite containing $2 \mathrm{wt} \%$ nano-silica exhibited less calcium hydroxide but slightly more $\mathrm{C}_{2} \mathrm{~S}$ than the control cement paste. 
On the other hand, as can be seen in Table 3 and Fig. 5e, the NCC1 cement nanocomposite shows lower amounts of $\mathrm{C}_{3} \mathrm{~S}$ and $\mathrm{C}_{2} \mathrm{~S}$ and also higher amount of $\mathrm{Ca}(\mathrm{OH})_{2}$ compared to $\mathrm{CNCC} 1$ cement nanocomposite but slightly higher amounts of $\mathrm{C}_{3} \mathrm{~S}$ and $\mathrm{C}_{2} \mathrm{~S}$ and also lower amount of $\mathrm{Ca}(\mathrm{OH})_{2}$ compared to $\mathrm{CNCC} 3$ cement nanocomposite. This result confirms that less pozzolanic reaction has occurred in NCC1 cement nanocomposite than $\mathrm{CNCC} 1$ cement nanocomposite. In contrast, as can be seen from Table 3 and Fig. 5d for cement nanocomposite containing $3 \mathrm{wt} \%$ CNC, the amount of $\mathrm{Ca}(\mathrm{OH})_{2}$ was decreased from $16.8 \mathrm{wt} \%$ to $14.1 \mathrm{wt} \%$, about $16 \%$ reduction compared to cement paste. Also the intensities of major peaks of $\mathrm{Ca}(\mathrm{OH})_{2}$ were slightly decreased compared to cement paste (Fig. 5 a and d). But this reduction of amount of $\mathrm{Ca}(\mathrm{OH})_{2}$ is less than the reduction in cement nanocomposite containing $1 \mathrm{wt} \% \mathrm{CNC}$. Moreover, the amounts of $\mathrm{C}_{3} \mathrm{~S}(1.4 \mathrm{wt} \%)$ and $\mathrm{C}_{2} \mathrm{~S}(5.4 \mathrm{wt} \%)$ are also lower than cement nanocomposite containing 1 wt\% CNC. This may be attributed to agglomerations of CNC at high contents which lead to relatively poor dispersion of $\mathrm{CNC}$ and hence relatively poor pozzolanic reaction [2, 30]. Table 3 also shows that the calcite content varies in all samples. For example, the content of calcite decreased from 3.7 to $2.1 \mathrm{wt} \%$ in cement nanocomposite containing $1 \mathrm{wt} \% \mathrm{CNC}$. This indicates that little carbonation occurred over the 56 day curing period. Table 3 shows that Ettringite is slightly less in cement nanocomposite than cement paste. For example, it decreased from 2.0 to $1.3 \mathrm{wt} \%$ in cement nanocomposite containing $1 \mathrm{wt} \% \mathrm{CNC}$.

\subsubsection{Calculation of $\mathrm{Ca}(\mathrm{OH})_{2}$ content in cement nanocomposite by the combination of QXDA} and TGA techniques

The $\mathrm{Ca}(\mathrm{OH})_{2}$ content $(\mathrm{CH})$ is calculated from the TGA curves using the following equation [31]:

$$
C H(\%)=W L_{C H}(\%) \frac{M W_{C H}}{M W_{\mathrm{H}_{2} \mathrm{O}}}
$$


Where $W L_{C H}(\%)$ is corresponds to the weight loss attributable to $\mathrm{Ca}(\mathrm{OH})_{2}$ decomposition, $M W_{C H}$ is the molecular weight of $\mathrm{CH}(74.01 \mathrm{~g} / \mathrm{mol})$ and $M W_{\mathrm{H}_{2} \mathrm{O}}$ is the molecular weight of $\mathrm{H}_{2} \mathrm{O}(18 \mathrm{~g} / \mathrm{mol})$. The thermograms (TGA) of cement paste and cement nanocomposite containing $\mathrm{CNC}$ and $\mathrm{NC}$ are shown in Fig. 6. Table 4 summarises the $\mathrm{CH}$ content of above measured by QXDA and TGA techniques. Results in Table 4 indicate that TGA is at least as good as QXDA for quantifying the amount of calcium hydroxide [27]. It can be seen that there is good agreement between the two techniques, where both measured amounts are very close to each other [28]. However, the amounts of CH by TGA are slightly lower than the QXDA. This observation is in agreement with the work done by Scrivenera et al [24] and Korpa et al. [32], in which they reported that this discrepancy could be attributed to the possible error sources of each method itself that were difficult to quantify. Nevertheless, inside the error margin there is a good correlation of the values assessed by both techniques employed [32]. And also the above consistency added a new evidence for reliability of the QXRD method to characterize quantitatively the hydration of cement systems [28]. The TGA and QXDA results in Table 4 also confirm the reactivity of $1 \mathrm{wt} \% \mathrm{CNC}$ in reducing the $\mathrm{CH}$ content in cement nanocomposite. The $\mathrm{CNC}$ is mainly amorphous material and behaves as a highly reactive artificial pozzolan. The $\mathrm{CH}$ content by the TGA and QXDA in cement nanocomposite containing $1 \mathrm{wt} \% \mathrm{CNC}$ was 10.7 and $12.1 \mathrm{wt} \%$, respectively. It is also be seen that the $\mathrm{CH}$ content in cement nanocomposite containing $1 \mathrm{wt} \% \mathrm{CNC}$ is reduced significantly when compared to cement paste and cement nanocomposite containing $\mathrm{NC}$ and $\mathrm{CNC}$ such as cement nanocomposite containing $1 \mathrm{wt} \% \mathrm{NC}$. This could be due to the reactivity of $1 \mathrm{wt} \% \mathrm{CNC}$ in cement nanocomposite and the consumption of $\mathrm{CH}$ by the pozzolanic reaction. 


\subsection{Porosity, water absorption and density}

The porosity, water absorption and density of cement paste and cement nanocomposite containing $\mathrm{NC}$ and $\mathrm{CNC}$ are shown in Table 5. It is noticed that the addition of $\mathrm{CNC}$ or $\mathrm{NC}$ decreases the porosity and water absorption of these cement nanocomposites when compared to control cement paste. In $\mathrm{CNCC} 1$ cement nanocomposite, the porosity and water absorption decreased by $31.2 \%$ and $34 \%$, respectively compared to cement paste. This indicates that $1 \mathrm{wt} \%$ $\mathrm{CNC}$ has a filling effect in the porosity of cement nanocomposite. This result is in agreement with the work done by Jo et al. [15] where the porosity of cement mortar is decreased by the addition of nano- $\mathrm{SiO}_{2}$ particles. Supit and Shaikh [33] reported that the addition of $2 \mathrm{wt} \%$ nanosilica significantly reduced the porosity of high volume fly ash (HVFA) concrete. Furthermore, In Table 5, the addition of $1 \mathrm{wt} \% \mathrm{CNC}$ increased the density of control cement paste from 1.76 to $1.93 \mathrm{~g} / \mathrm{cm}^{3}$, about $9.7 \%$ increase. This improvement demonstrates that cement nanocomposite with $1 \mathrm{wt} \% \mathrm{CNC}$ yields consolidated denser microstructure. However, further addition of CNC or NC leads to an increase in porosity and water absorption and a decrease in density. This could be attributed to the poor dispersion and agglomerations of the high $\mathrm{CNC}$ or $\mathrm{NC}$ contents which create more voids in the matrix $[3,34]$.

SEM examinations of the microstructure of cement paste, $\mathrm{CNCC} 1$ and $\mathrm{CNCC} 3$ cement nanocomposite are shown in Figs. 7 a-c. For cement paste, Fig. 7a shows more $\mathrm{Ca}(\mathrm{OH})_{2}$ crystals and Ettringite as well as more pores which revealed a weak structure. Fig. $7 \mathrm{~b}$ shows the SEM micrograph of $\mathrm{CNCC} 1$, which is different from that of cement paste, the structure is dense and compact with few pores and more C-S-H gel. On the other hand, in Fig. 7c, the CNCC3 shows more pores than $\mathrm{CNCC} 1$ which relatively weaken the structure. 


\subsection{Mechanical properties}

\subsubsection{Compressive strength}

The compressive strength of the cement paste, cement nanocomposite containing NCC and CNCC are presented in Fig. 8. It can be noticed from results in Fig. 8 that the addition of NC and $\mathrm{CNC}$ to cement paste increases the compressive strength of all cement nanocomposite pastes. For instance, the cement nanocomposite containing $1 \mathrm{wt} \% \mathrm{CNC}$ exhibited an enhancement in the compressive strength from 53.1 to $74.2 \mathrm{MPa}$ or $40 \%$ increase, whereas in the cement nanocomposite containing $1 \mathrm{wt} \% \mathrm{NC}$, the compressive strength reached $69.8 \mathrm{MPa}$. The increase in compressive strength of cement nanocomposite containing $1 \mathrm{wt} \% \mathrm{CNC}$ is due to amorphous state of $\mathrm{CNC}$ (i.e. small particle size) and extremely large surface area, in which the $\mathrm{CNC}$ reacts more quickly with free lime in the hydration reaction than $\mathrm{NC}$ and subsequently produced more secondary $\mathrm{C}-\mathrm{S}-\mathrm{H}$ gel and filled the capillary pores in the matrix efficiently $[2,35]$. Thus the microstructure of the matrix is densified by the nanoparticles. Chang [36] reported that the addition of $0.6 \mathrm{wt} \%$ nano-montmorillonite into cement paste increased compressive at age of 56 days from 46 to $52.1 \mathrm{MPa}$ (i.e. $13.2 \%$ increases) compared to the cement paste. Li et al. [37] noticed $26 \%$ improvement in 28 days compressive strength of cement mortar containing $3 \%$ nano silica. Despite benefits of CNC and NC, it is important to note that the nano particles have a tendency to agglomerate when using at high content (i.e. more $3 \mathrm{wt} \% \mathrm{CNC}$ ) in the mixes $[3,38]$. This aggregation forms weak zones and consequently prevents the formation of homogenous hydrate microstructure. Therefore, the appropriate proportion of $\mathrm{CNC}$ content should be taken into account.

\subsubsection{Flexural strength}


Flexural strengths of cement paste, cement nanocomposite containing NC and CNC are shown in Fig. 9. Overall, the incorporation of $\mathrm{CNC}$ or $\mathrm{NC}$ into the cement matrix led to significant enhancement in the flexural strength of all cement nanocomposites. The flexural strength of cement nanocomposite containing 1, 2 and $3 \mathrm{wt} \% \mathrm{CNC}$ is increased by $42.9 \%, 34.8 \%$ and $30.6 \%$, respectively compared to cement paste. While the flexural strength of cement nanocomposite containing 1, 2 and $3 \mathrm{wt} \% \mathrm{NC}$ is increased by $32.1 \%, 29.3 \%$ and $24.7 \%$ respectively compared to cement paste. This improvement clearly indicates the effectiveness of CNC in consuming calcium hydroxide $(\mathrm{CH})$, supporting pozzolanic reaction and filling the micro pores in the matrix $[2,38]$. Thus the microstructure of cement nanocomposite is denser than the cement matrix, especially in the case of using $1 \mathrm{wt} \% \mathrm{CNC}$, which is evident from its higher flexural strength. Hosseini et al. [39] studied the effect of nanoclay (Cloisite15A) on the mechanical properties of cement mortar at 28 days with water/binder ratio of 0.4 . They reported that addition of $1 \mathrm{wt} \%$ nanoclay improved the flexural strength from 7.0 to $9.1 \mathrm{MPa}$, about $30 \%$ increase. Qing et al. [13] studied the influence of $3 \mathrm{wt} \%$ nano- $\mathrm{SiO}_{2}$ (NS) addition on properties of hardened cement paste. They observed that the flexural strength increased by about $72 \%$ compared to control cement matrix. They attributed this improvement to the pozzolanic and filler effects of nano- $\mathrm{SiO}_{2}$ particles.

However, the addition of more than $1 \mathrm{wt} \% \mathrm{CNC}$ caused a marked reduction in the flexural strength. This could be attributed to the relatively poor dispersion and agglomerations of the $\mathrm{CNC}$ in the cement matrix at higher CNC contents, which create weak zones, in the form of micro-voids which cause stress concentration [2, 40]. Moreover, the addition of more CNC (i.e. $2 \mathrm{wt} \%$ ) led to a significant reduction in the flexural strength due to an increase in porosity. Nevertheless the addition of CNC improved the flexural strength of cement nanocomposite. For 
example, in this study, although the flexural strength of cement nanocomposite with $3 \mathrm{wt} \% \mathrm{CNC}$ decreased compared to cement nanocomposite with $1 \mathrm{wt} \% \mathrm{CNC}$ but it is still higher than the control cement paste.

\subsubsection{Fracture toughness}

Fracture toughness of cement paste and cement nanocomposite containing NCC and $\mathrm{CNCC}$ are shown in Fig. 10. As shown in Fig. 10, the fracture toughness of cement nanocomposite containing 1,2 and $3 \mathrm{wt} \% \mathrm{CNC}$ were $0.49,0.47$ and $0.44 \mathrm{MPa} \cdot \mathrm{m}^{1 / 2}$, respectively. It can be seen that the fracture toughness of $\mathrm{CNCC} 1$ cement nanocomposite is increased by $40 \%$ compared to cement paste. This is attributed to the fact that the $\mathrm{CNC}$ modified the matrix through pozzolanic reaction and reduced the $\mathrm{Ca}(\mathrm{OH})_{2}$ content. Alamri and Low [41] reported that the addition of 1 wt\% halloysite nanotubes (HNTs) into epoxy matrix significantly increased the fracture toughness from 0.85 to $1.33 \mathrm{MPa} . \mathrm{m}^{1 / 2}$ (i.e. by $56.5 \%$ ) compared to epoxy matrix. However, facture toughness of CNCC cement nanocomposite gradually decreased when CNC contents are increased after the optimum content of $1 \mathrm{wt} \%$. This is attributed to the poor dispersion of high content of CNC into the matrix, which leads to increase in porosity $[4,42]$.

\subsubsection{Impact strength}

The impact strength is defined as the ability of the material to withstand impact loading [43]. The impact strengths of cement paste and cement nanocomposite containing NCC and CNCC are shown in Table 6. Generally, it can be seen that the impact strength of cement paste is significantly improved due to the addition of $\mathrm{CNC}$ or NC. The impact strength of NCC1 cement nanocomposite is $3.1 \mathrm{KJ} / \mathrm{m}^{2}$, about $29.4 \%$ increase compared to the cement paste. While the impact strength of $\mathrm{CNCC} 1$ cement nanocomposite is $3.2 \mathrm{KJ} / \mathrm{m}^{2}$, about $33.6 \%$ increase compared 
to cement paste. Alamri and Low [44] reported that the addition of $5 \mathrm{wt} \%$ nanoclay to epoxy matrix increased the impact strength from 5.6 to $7.8 \mathrm{~kJ} / \mathrm{m}^{2}$ about $39.3 \%$ increase compared to epoxy matrix. However, as CNC loading increased after the optimum content of $1 \mathrm{wt} \%$ the impact strength is decreased. For example, the impact strength of $\mathrm{CNCC} 3$ cement nanocomposite was $3.1 \mathrm{KJ} / \mathrm{m}^{2}$, about $4 \%$ decrease compared to $\mathrm{CNCC} 1$ cement nanocomposite. This reduction in impact strength at higher $\mathrm{CNC}$ loading was due to the formation of $\mathrm{CNC}$ agglomerates and voids which led to weaken nanocomposite [3].

\subsubsection{Rockwell Hardness}

The Rockwell hardness of cement paste and cement nanocomposite containing NCC and CNCC are shown in Table 6. Generally, the addition of $\mathrm{CNC}$ or $\mathrm{NC}$ into the cement matrix led to significant enhancement in the Rockwell hardness of all cement nanocomposites. As shown in Table 6 the Rockwell hardness of cement nanocomposite containing 1, 2 and 3 wt\% CNC were 91.3, 89.0 and 86.3 HRH, respectively, which corresponds to about $31.1 \%, 27.7 \%$ and $23.9 \%$, respectively increase compared to cement paste. While the Rockwell hardness of cement nanocomposite containing 1, 2 and $3 \mathrm{wt} \% \mathrm{NC}$ is increased by $25.3 \%, 21.0 \%$ and $18.6 \%$ respectively compared to the cement paste. This improvement demonstrates that the microstructure of cement nanocomposite is denser than the cement matrix, especially in the case of using $1 \mathrm{wt} \% \mathrm{CNC}$. That is because of the efficiency of $\mathrm{CNC}$ in promoting pozzolanic reaction and filling effect $[3,45,46]$. In an analogous research, Gupta et al. [47] reported that the hardness number $(\mathrm{HRH})$ of the $\mathrm{Fe}-\mathrm{Al}_{2} \mathrm{O}_{3}$ metal matrix nanocomposite was much higher in comparison to the cast iron specimen. However, the addition of high CNC or NC contents e.g. $3 \%$ did not show any improvement in the hardness when compared to $1 \mathrm{wt} \% \mathrm{CNC}$ [4]. 


\subsection{Thermal stability}

Weight loss (\%) curves of cement paste and cement nanocomposite containing CNCC and NCC1 are shown in Fig. 11. The char yields at different temperatures are summarized in Table 7. The TGA analysis shows three distinct stages of decomposition in these samples. The first stage of decomposition is between room temperature and $230{ }^{\circ} \mathrm{C}$, which may be related to the decomposition of Ettringite and dehydration of C-S-H gel (loss of water). The second stage of decomposition is between $400{ }^{\circ} \mathrm{C}$ and $510{ }^{\circ} \mathrm{C}$, which corresponds to $\mathrm{Ca}(\mathrm{OH})_{2}$ decomposition. The third stage of decomposition is between $670{ }^{\circ} \mathrm{C}$ and $780{ }^{\circ} \mathrm{C}$, which correspond to $\mathrm{CaCO}_{3}$ decomposition $[48,49]$. In the first stage, generally all cement nanocomposites exhibited slightly better thermal stability than cement paste due to higher resistance of $\mathrm{CNC}$ or $\mathrm{NC}$ to decomposition [3,5]. Concerning the cement nanocomposite containing CNCC in second and third stage, the $\mathrm{CNCC} 1$ cement nanocomposite shows better thermal stability than $\mathrm{CNCC}$, $\mathrm{CNCC} 3$ and NCC1 cement nanocomposite due to dense and compact nanocomposite through consumption of calcium hydroxide and formation of secondary CSH gels during pozzolanic reaction [28]. In contrast, $\mathrm{NCC1}$ cement nanocomposite shows lower thermal stability than CNCC2 cement nanocomposite but slightly higher than CNCC3 cement nanocomposite. This result confirms that slightly poor pozzolanic reaction has occurred and hence this NCC1 nanocomposite is less dense when compared to $\mathrm{CNCC} 1$ and $\mathrm{CNCC} 2$ cement nanocomposites. From Table 7 at $1000{ }^{\circ} \mathrm{C}$, the char residue of cement paste, $\mathrm{CNCC} 1, \mathrm{CNCC} 2$ and $\mathrm{CNCC} 3$ cement nanocomposite was about 74.6, 77.1, 76.7 and $75.9 \mathrm{wt} \%$, respectively. It can be seen that the $\mathrm{CNCC} 1$ cement nanocomposite performed better in thermal stability with higher char residue of about $3.3 \%$ and $1.5 \%$ more than cement paste and $\mathrm{CNCC} 3$ cement nanocomposite, 
respectively. In a similar study, Chen et al. [50] reported that addition of $10 \mathrm{wt} \%$ nano- $\mathrm{TiO}_{2}$ into cement paste improved the thermal stability of cement nanocomposite considerably.

\section{Cost-benefit analysis and Applications}

There is a huge optimism on the use of nanomaterials in construction and building applications although the nanoparticles are expensive and could limit their applications $[1,51]$. However, nano particles exhibit unique characteristics which result in new generation of concrete that is stronger and more durable [52]. With progress of manufacturing technologies the cost of nano particles is also expected to drop in future. Moreover, the nanoparticles are used in very small amount in the concrete or other cementitious nanocomposites. For example, in this study $1 \mathrm{wt} \%$ calcined nanoclay in cement nanocomposite led significant improvement in mechanical properties. From economic point of view, the addition of $1 \%$ calcined nanoclay in cement nanocomposite will not add any significant cost but improved the mechanical properties by about 40\%. Shaikh and Supit [28] stated that although the use of nano- $\mathrm{CaCO}_{3}$ was first considered as filler to partially replace cement or gypsum, some studies have shown advantages of using $1 \%$ nano- $\mathrm{CaCO}_{3}$ nanoparticles in terms of compressive strength, accelerating effect and economic benefits as compared to cement and other supplementary cementitious materials.

\section{Conclusions}

The influence of nanoclay (NC) and calcined nanoclay (CNC) on the microstructures, mechanical and thermal properties of cement nanocomposite has been presented. Results of the combination of QXDA and TGA techniques indicate that TGA is at least as good as QXDA for quantifying the amount of $\mathrm{Ca}(\mathrm{OH})_{2}$. The optimum content of $\mathrm{CNC}$ was found to be $1 \mathrm{wt} \%$. The cement nanocomposite containing $1 \mathrm{wt} \% \mathrm{CNC}$ decreased the porosity (by $31.2 \%$ ), water 
absorption (by 34\%) and increased the density (by 9.7\%), compressive strength (by 40\%) flexural strength (by 42.9\%), fracture toughness (by 40\%), impact strength (by 33.6\%) and Rockwell hardness (by 31.1\%) as well as improved thermal stability (by 3.3\%) compared to the control cement paste. The microstructural analysis such as QXDA and SEM showed that the addition of $1 \mathrm{wt} \% \mathrm{CNC}$ in cement matrix enhanced the microstructure of cement nanocomposite through the filler and pozzolanic reaction effects. However, the addition of more NC or CNC (beyond $1 \mathrm{wt} \%$ ) into cement nanocomposite adversely affected the mechanical and thermal properties. In fact, it could be recommended that much research is needed to overcome the agglomerations of $\mathrm{NC}$ or $\mathrm{CNC}$ and identify the best method of mixing which leads to good dispersion of CNC in the matrix.

\section{Acknowledgments}

The authors are grateful to Ms E. Miller from Applied Physics for assistance with SEM.

\section{References}

[1] Sanchez F, Sobolev K. Nanotechnology in concrete - A review. Constr Build Mater 2010;24(11):2060-71.

[2] Hakamy A, Shaikh F.U.A, Low I.M. Characteristics of hemp fabric reinforced nanoclaycement nanocomposites. Cem Concr Compos 2014;50:27-35.

[3] Hakamy A, Shaikh F.U.A, Low I.M. Thermal and mechanical properties of hemp fabricreinforced nanoclay-cement nanocomposites. J Mater Sci 2014;49(4):1684-94.

[4] Hakamy A, Shaikh F.U.A, Low I.M. Microstructures and mechanical properties of hemp fabric reinforced organoclay-cement nanocomposites. Constr Build Mater 2013;49:298307.

[5] Alhuthali A, Low IM, Dong C. Characterization of the water absorption, mechanical and thermal properties of recycled cellulose fibre reinforced vinyl-ester eco-nanocomposites. Compos Part B 2012;43(7):2772-81. 
[6] Nazari A, Riahi S. The effects of zinc oxide nanoparticles on flexural strength of selfcompacting concrete. Compos Part B 2011;42(2):167-75.

[7] Morsy MS, Alsayed SH, Aqel M. Hybrid effect of carbon nanotube and nano-clay on physico-mechanical properties of cement mortar. Constr Build Mater 2011;25(1):145-49.

[8] Li H, Xiao H, Guan X, Wang Z, Yu L. Chloride diffusion in concrete containing nano$\mathrm{TiO}_{2}$ under coupled effect of scouring. Compos Part B 2014;56:698-704.

[9] Nazari A, Riahi S. The effects of $\mathrm{ZrO}_{2}$ nanoparticles on properties of concrete using ground granulated blast furnace slag as binder. J Compos Mater 2012;46(9):1079-90.

[10] Moradpour R, Taheri-Nassaj E, Parhizkar T, Ghodsian M. The effects of nanoscale expansive agents on the mechanical properties of non-shrink cement-based composites: The influence of nano-MgO addition. Compos Part B 2013;55:193-202.

[11] Supit S, Shaikh, FUA. Effect of nano- $\mathrm{CaCO}_{3}$ mon compressive strength development of high volume fly ash mortars and concretes. J Adv Concr Technol 2014;12(6):178-86.

[12] Hou P, Kawashima S, Kong D, Corr D, Qian J, Shah S. Modification effects of colloidal nano- $\mathrm{SiO}_{2}$ on cement hydration and its gel property. Compos Part B 2013;45(1):440-8.

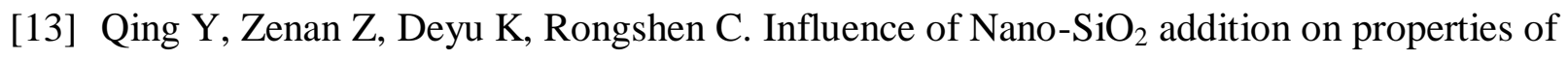
hardened cement paste as compared with silica fume. Constr Build Mater 2007;21(3):539545.

[14] Zhang MH, Islam J. Use of nano-silica to reduce setting time and increase earlystrength of concretes with high volume fly ash or slag. Constr Build Mater 2012;29:573-80.

[15] Jo BW, Kim CH, Lim JH. Characteristics of cement mortar with nano-silica particles. ACI Mater J 2007;104(4):404-7.

[16] Phoo-ngernkham T, Chindaprasirt P, Sata V, Hanjitsuwan S. The effect of adding nanosilica and nano-alumina on properties of high calcium fly ash geopolymer cured at ambient temperature. Mater Des 2014;55:58-65.

[17] Aly M, Hashmi MSJ, Olabi AG, Messeiry M, Hussain AI. Effect of nano clay particles on mechanical, thermal and physical behaviours of waste glass cement mortars. Mater Sci Eng A 2011;528(27):7991-8.

[18] Alamri H, Low IM, Alothman Z. Mechanical, thermal and microstructural characteristics of cellulose fibre reinforced epoxy/organoclay nanocomposites. Compos Part B 2012;43(7):2762-71. 
[19] Wei J, Meyer C. Sisal fiber-reinforced cement composite with Portland cement substitution by a combination of metakaolin and nanoclay. J Mater Sci 2014;49(21):760419.

[20] Farzadnia N, Ali A, Demirboga R, Anwar M. Effect of halloysite nanoclay on mechanical properties, thermal behavior and microstructure of cement mortars. Cem Concr Res 2013;48:97-104.

[21] ASTM C-1365-06. Standard test method for determination of the proportion of phases in Portland cement and Portland-cement clinker using X-ray powder diffraction analysis. 2011.

[22] Taylor HFW. Cement Chemistry. London: Academic press limited, 1990.

[23] Aldridge A. Accuracy and precision of phase analysis in Portland cement by Bogue, microscopic and x-ray diffraction methods. Cem Concr Res 1982;12(3):381-98.

[24] Scrivenera K, Fullmanna T, Galluccia E, Walentab G, Bermejob E. Quantitative study of Portland cement hydration by X-ray diffraction/Rietveld analysis and independent methods. Cem Concr Res 2004;34(9):1541-7.

[25] ASTM C-20. Standard test methods for apparent porosity, water absorption, apparent specific gravity, and bulk density of burned refractory brick and shapes by boiling water. 2010.

[26] He C, Makovicky E, Osbaeck B. Thermal treatment and pozzolanic activity of Na- and Ca-montmorillonite. Appl Clay Sci 1996;10(5):351-68.

[27] Soin A, Catalan L, Kinrade S. A combined QXRD/TG method to quantify the phase composition of hydrated Portland cements. Cem Concr Res 2013;48:17-24.

[28] Wei Y, Yao W, Xing X, Wu M. Quantitative evaluation of hydrated cement modified by silica fume using QXRD, 27Al MAS NMR, TG-DSC and selective dissolution techniques. Constr Build Mater 2012;36:925-32.

[29] Shaikh FUA, Supit SWM, Sarker PK. A study on the effect of nano silica on compressive strength of high volume fly ash mortars and concretes. Mater Des 2014;60:433-42.

[30] Najigivi A, Khaloo A, Iraji A, Abdul-Rashid S. Investigating the effects of using different types of $\mathrm{SiO}_{2}$ nanoparticles on the mechanical properties of binary blended concrete. Compos Part B 2013;54:52-8. 
[31] Shaikh, FUA and S. Supit. Mechanical and durability properties of high volume fly ash (HVFA) concrete containing calcium carbonate $\left(\mathrm{CaCO}_{3}\right)$ nanoparticles. Constr Build Mater 2014;70:309-21.

[32] Korpa A, Kowald T, Trettin R. Phase development in normal and ultra-high performance cementitious systems by quantitative $\mathrm{X}$-ray analysis and thermoanalytical methods. Cem Concr Res 2009;39(2):69-76.

[33] Supit SWM, Shaikh FUA. Durability properties of high volume fly ash concrete containing nano-silica. Mater Struct 2014; doi 10.1617/s115270140329-0.

[34] Senff L, Tobaldi D, Lucas S, Hotza D, Ferreira V, Labrincha J. Formulation of mortars with nano- $\mathrm{SiO}_{2}$ and nano- $\mathrm{TiO}_{2}$ for degradation of pollutants in buildings. Compos Part $\mathrm{B}$ 2013;44(1):40-7.

[35] Stefanidou M, Papayianni I. Influence of nano- $\mathrm{SiO}_{2}$ on the Portland cement pastes. Compos Part B 2012;43(6):2706-10.

[36] Chang T, Shih J, Yang K, Hsiao T. Material properties of portland cement paste with nano-montmorillonite. J Mater Sci 2007;42(17):7478-87.

[37] Li H, Xiao H, Yuan J, Ou J. Microstructure of cement mortar with nano-particles. Compos Part B 2004;35(2):185-9.

[38] Shebl S, Allie L, Morsy M, Aglan H. Mechanical behavior of activated nano silicate filled cement binders. J Mater Sci 2009;44(6):1600-6.

[39] Hosseini P, Hosseinpourpia R, Pajum A, Khodavirdi M, Izadi H, Vaezi A. Effect of nanoparticles and aminosilane interaction on the performances of cement-based composites: An experimental study. Constr Build Mater 2014;66:113-24.

[40] Givi A, Abdul-Rashid S, Aziz F, Salleh M. Experimental investigation of the size effects of $\mathrm{SiO}_{2}$ nano-particles on the mechanical properties of binary blended concrete. Compos Part B 2010;41(8): 673-7.

[41] Alamri H, Low IM. Microstructural, mechanical, and thermal characteristics of recycled cellulose fiber-halloysite-epoxy hybrid composites. Polym Compos 2012;33(4):589-600.

[42] Givi A, Abdul-Rashid S, Aziz F, Salleh M. The effects of lime solution on the properties of $\mathrm{SiO}_{2}$ nanoparticles binary blended concrete. Compos Part B 2011;42(3):562-9.

[43] Zhou X, Ghaffar S, Dong W, Oladiran O, Fan M. Fracture and impact properties of short discrete jute-fiber reinforced cementitious composites. Mater Des 2013;49:35-47. 
[44] Alamri H, Low I.M. Effect of water absorption on the mechanical properties of nano-filler reinforced epoxy nanocomposites. Mater Des 2012;42:214-22.

[45] Yu M, George C, Cao Y, Wootton D, Zhou J. Microstructure, corrosion, and mechanical properties of compression-molded zinc-nanodiamond composites. J Mater Sci 2014;49(10):3629-41 .

[46] Karimzadeh A, Ayatollahi M. Investigation of mechanical and tribological properties of bone cement by nano-indentation and nano-scratch experiments. Polym Test 2012;31(6):828-33.

[47] Gupta P,1 Kumar D, Parkash O, Jha A. Sintering and Hardness Behavior of Fe- $\mathrm{Al}_{2} \mathrm{O}_{3}$ Metal Matrix Nanocomposites Prepared by Powder Metallurgy. J Compos 2014; doi.org/10.1155/2014/145973.

[48] Lothenbach B, Winnefeld F, Alder C, Wieland E, Lunk P. Effect of temperature on the pore solution, microstructure and hydration products of Portland cement pastes. Cem Concr Res 2007;37(4):483-91.

[49] Djaknoun S, Ouedraogo E, Benyahia A. Characterisation of the behaviour of high performance mortar subjected to high temperatures. Constr Build Mater 2012;28(1):17686.

[50] Chen J, Kou S, Poon C. Hydration and properties of nano- $\mathrm{TiO}_{2}$ blended cement composites. Cem Concr Compos 2012;34(5):642-9.

[51] Pacheco-Torgal F, Jalali S. Nanotechnology: Advantages and drawbacks in the field of construction and building materials. Constr Build Mater 2011;25(2):582-90.

[52] Singh T. A review of nanomaterials in civil engineering works. Inter J Struct Civ Eng Res 2014;3:31-5. 


\section{Figure Captions}

1. X-ray diffraction patterns of nanoclay and calcined nanoclay.

2. EDS analysis with SEM images of: (a) nanoclay, (b) calcined nanoclay (at $900{ }^{\circ} \mathrm{C}$ ).

3. Chemical structure of quaternary ammonium salt.

4. TEM images of nanoclay and calcined nanoclay $\left(\right.$ at $\left.900{ }^{\circ} \mathrm{C}\right)$ at: $(\mathrm{a}, \mathrm{c})$ low magnification, (b, d) high magnification.

5. XRD patterns of: (a) cement paste, cement nanocomposite containing: (b) $1 \mathrm{wt} \% \mathrm{CNC}$ (CNCC1), (c) 2 wt\% CNC (CNCC2), (d) 3 wt $\%$ CNC (CNCC3), (e) 1 wt \% NC (NCC1). Numbers indicate to: $1=$ Corundum $\left[\mathrm{Al}_{2} \mathrm{O}_{3}\right]$ phase, $2=$ Portlandite $\left[\mathrm{Ca}(\mathrm{OH})_{2}\right]$ phase, $3=$ Tricalcium silicate $\left[\mathrm{C}_{3} \mathrm{~S}\right]$ phase, $4=$ Dicalcium silicate $\left[\mathrm{C}_{2} \mathrm{~S}\right]$ phase, $5=$ Ettringite phase, $6=$ Gypsum phase, $7=$ Quartz phase, $8=$ Calcite phase .

6. TGA curves of cement paste (C) and cement nanocomposite: $\mathrm{CNCC} 1, \mathrm{CNCC} 2, \mathrm{CNCC} 3$ and NCC1.

7. SEM micrographs of: (a) cement paste, cement nanocomposite containing: (b) $1 \mathrm{wt} \%$ CNC, (c) 3 wt $\%$ CNC. Numbers indicate to: $1=\left[\mathrm{Ca}(\mathrm{OH})_{2}\right]$ crystals, $2=$ Ettringite, 3=pores, 4=C-S-H gel.

8. Compressive strength as a function of calcined nanoclay (or nanoclay) content for cement paste and cement nanocomposite.

9. Flexural strength as a function of calcined nanoclay (or nanoclay) content for cement paste and cement nanocomposite.

10. Fracture toughness as a function of calcined nanoclay (or nanoclay) content for cement paste and cement nanocomposite. 
11. Weight loss (\%) curves by TGA of cement paste (C) and cement nanocomposite: $\mathrm{CNCC} 1, \mathrm{CNCC} 2, \mathrm{CNCC} 3$ and $\mathrm{NCC} 1$. 


\section{Table 1}

Physical properties of the nanoclay platelets (Cloisite 30B)

\begin{tabular}{ll}
\hline Physical properties of the (Cloisite $30 \mathrm{~B})$ \\
\hline Colour & Off white \\
Density $\left(\mathrm{g} / \mathrm{cm}^{3}\right)$ & 1.98 \\
d-spacing $(001)(\mathrm{nm})$ & 1.85 \\
Aspect ratio & $200-1000$ \\
Surface area $\left(\mathrm{m}^{2} / \mathrm{g}\right)$ & 750 \\
Mean particle size $(\mu \mathrm{m})$ & 6 \\
\hline
\end{tabular}

Table 2

Mix proportions of specimens

\begin{tabular}{ccccc}
\hline & \multicolumn{4}{c}{ Mix proportions (wt \%) } \\
\cline { 2 - 5 } Sample & Cement & NC & CNC & Water/binder \\
\hline C & 100 & 0 & 0 & 0.485 \\
NCC1 & 99 & 1 & 0 & 0.485 \\
NCC2 & 98 & 2 & 0 & 0.485 \\
NCC3 & 97 & 3 & 0 & 0.485 \\
CNCC1 & 99 & 0 & 1 & 0.485 \\
CNCC2 & 98 & 0 & 2 & 0.485 \\
CNCC3 & 97 & 0 & 3 & 0.485 \\
\hline
\end{tabular}


Table 3

QXDA results for cement paste (C) and cement nanocomposite containing 1, 2 and $3 \mathrm{wt} \% \mathrm{CNC}$ and $1 \mathrm{wt} \% \mathrm{NC}$.

\begin{tabular}{lccccc}
\hline & \multicolumn{4}{c}{ Weight \% (Phase abundance) } \\
\cline { 2 - 6 } Phase & $\mathrm{C}$ & CNCC1 & CNCC2 & CNCC3 & NCC1 \\
\hline Portlandite $\left[\mathrm{Ca}(\mathrm{OH})_{2}\right]$ & 16.8 & 12.1 & 13.2 & 14.1 & 13.8 \\
Ettringite $\left[\mathrm{Ca}_{6} \mathrm{Al}_{2}\left(\mathrm{SO}_{4}\right)_{3}(\mathrm{OH})_{12} .26 \mathrm{H}_{2} \mathrm{O}\right]$ & 2.0 & 1.3 & 1.5 & 1.8 & 1.6 \\
Tricalcium silicate $\left[\mathrm{C}_{3} \mathrm{~S}\right]$ & 1.3 & 2.0 & 1.7 & 1.4 & 1.5 \\
Dicalcium silicate $\left[\mathrm{C}_{2} \mathrm{~S}\right]$ & 4.4 & 6.6 & 6.1 & 5.4 & 6.1 \\
Gypsum $\left[\mathrm{Ca}\left(\mathrm{SO}_{4}\right)\left(\mathrm{H}_{2} \mathrm{O}\right)_{2}\right]$ & 0.7 & 0.4 & 0.6 & 0.4 & 0.4 \\
Calcite $\left[\mathrm{CaCO}_{3}\right]$ & 3.7 & 2.1 & 2.7 & 3.3 & 3.0 \\
Quartz $\left[\mathrm{SiO}_{2}\right]$ & 0.9 & 0.6 & 0.4 & 0.7 & 0.5 \\
Amorphous content & 70.1 & 74.8 & 73.7 & 72.8 & 73.0 \\
\hline
\end{tabular}

Table 4

Calculation of $\mathrm{Ca}(\mathrm{OH})_{2}$ content in cement paste and cement nanocomposite containing 1, 2 and $3 \mathrm{wt} \% \mathrm{CNC}$ and $1 \mathrm{wt} \% \mathrm{NC}$ by QXDA and TGA techniques

\begin{tabular}{|c|c|c|c|}
\hline Sample & TGA (wt \%) & QXRD (wt \%) & Difference (wt \%) \\
\hline $\mathrm{C}$ & 15.5 & 16.8 & 1.3 \\
\hline CNCC1 & 10.7 & 12.1 & 1.4 \\
\hline $\mathrm{CNCC} 2$ & 12.1 & 13.2 & 1.1 \\
\hline CNCC3 & 13.0 & 14.1 & 1.1 \\
\hline $\mathrm{NCC} 1$ & 12.3 & 13.8 & 1.5 \\
\hline
\end{tabular}




\section{Table 5}

Porosity, density and water absorption values for cement paste (C), (NCC) cement nanocomposite containing $\mathrm{NC}$ and (CNCC) cement nanocomposite containing CNC.

\begin{tabular}{|c|c|c|c|}
\hline Sample & Porosity (\%) & Density $\left(\mathrm{g} / \mathrm{cm}^{3}\right)$ & Water absorption (\%) \\
\hline $\mathrm{C}$ & 23.9 & 1.76 & 13.4 \\
\hline NCC1 & 18.7 & 1.87 & 10.2 \\
\hline NCC2 & 19.6 & 1.78 & 11.0 \\
\hline NCC3 & 19.9 & 1.76 & 11.3 \\
\hline CNCC1 & 16.5 & 1.93 & 8.9 \\
\hline $\mathrm{CNCC} 2$ & 17.6 & 1.91 & 9.6 \\
\hline CNCC3 & 18.9 & 1.85 & 10.3 \\
\hline
\end{tabular}

Table 6

Impact strength and Rockwell hardness values for cement paste (C), (NCC) cement nanocomposite containing $\mathrm{NC}$ and (CNCC) cement nanocomposite containing CNC.

\begin{tabular}{|c|c|c|}
\hline Sample & Impact strength $\left(\mathrm{kJ} / \mathrm{m}^{2}\right)$ & Rockwell hardness (HRH) \\
\hline $\mathrm{C}$ & $2.38 \pm 0.06$ & $70 \pm 1$ \\
\hline $\mathrm{NCC} 1$ & $3.08 \pm 0.15$ & $87 \pm 2$ \\
\hline $\mathrm{NCC} 2$ & $3.01 \pm 0.11$ & $84 \pm 1$ \\
\hline NCC3 & $2.92 \pm 0.08$ & $83 \pm 1$ \\
\hline $\mathrm{CNCC} 1$ & $3.18 \pm 0.05$ & $91 \pm 1$ \\
\hline $\mathrm{CNCC} 2$ & $3.14 \pm 0.08$ & $89 \pm 1$ \\
\hline CNCC3 & $3.05 \pm 0.14$ & $86 \pm 2$ \\
\hline
\end{tabular}




\section{Table 7}

Thermal properties of cement paste (C) and cement nanocomposite containing 1, 2 and 3 wt \% CNC and cement nanocomposite containing $1 \mathrm{wt} \% \mathrm{NC}$.

\begin{tabular}{cccccccccccc}
\hline & \multicolumn{8}{c}{ Char yield $(\%)$ at different temperature $\left({ }^{\circ} \mathrm{C}\right)$} \\
\cline { 2 - 11 } Sample & & 100 & 200 & 300 & 400 & 500 & 600 & 700 & 800 & 900 & 1000 \\
\cline { 5 - 12 } C & & 95.82 & 88.82 & 86.03 & 83.57 & 79.57 & 78.44 & 76.37 & 75.69 & 75.09 & 74.61 \\
CNCC1 & & 96.19 & 89.32 & 86.83 & 84.88 & 81.75 & 80.86 & 79.01 & 78.33 & 77.61 & 77.10 \\
CNCC2 & 96.02 & 89.20 & 86.59 & 84.57 & 81.04 & 80.09 & 78.51 & 77.86 & 77.18 & 76.67 \\
CNCC3 & 95.82 & 88.82 & 86.03 & 83.96 & 80.03 & 79.02 & 77.60 & 77.05 & 76.45 & 75.93 \\
NCC1 & 95.72 & 89.10 & 86.37 & 83.96 & 80.56 & 79.60 & 78.12 & 77.49 & 76.85 & 76.35 \\
\hline
\end{tabular}

